LETTER TO JMG

\title{
Loci for primary ciliary dyskinesia map to chromosome 16p12.1-12.2 and 15q13.1-15.1 in Faroe Islands and Israeli Druze genetic isolates
}

\author{
D Jeganathan*, R Chodhari*, M Meekst, O Færoe, D Smyth, K Nielsen, I Amirav, A S Luder, \\ H Bisgaard, R M Gardiner, E M K Chung, H M Mitchison
}

J Med Genet 2004;41:233-240. doi: 10.1136/jmg.2003.014084

P rimary ciliary dyskinesia (PCD; Immotile cilia syndrome; OMIM 242650) is an autosomal recessive disorder resulting from dysmotility of cilia and sperm flagella. Cilia and flagella function either to create circulation of fluid over a stationary cell surface or to propel a cell through fluid..$^{3}$ These related structures are highly complex organelles composed of over 200 different polypeptides. ${ }^{45}$ The core or axoneme of cilia and flagella comprises a bundle of microtubules and many associated proteins. The microtubules are formed from $\alpha$ and $\beta$ tubulin protofilaments and are arranged in a well recognised ' $9+2$ ' pattern: nine peripheral microtubule doublets in a ring connected around a central pair of microtubules by radial spoke proteins. The peripheral microtubules have dynein motor proteins attached and are connected with each other by nexin links. ${ }^{6-8}$

In human beings, ciliated epithelium can be found lining the respiratory tract, including the sinuses and middle ear, the brain ependyma, the female oviduct, and the male vas deferens. Cilia in the respiratory tract play an important part in airway clearance of respiratory secretions. In primary ciliary dyskinesia, impaired mucociliary clearance causes recurrent respiratory tract infections including chronic otitis media, rhinitis, and sinusitus, often leading to permanent lung damage (bronchiectasis). ${ }^{\text {Patients }}$ are also often subfertile due to sperm tail immotility and immotile oviduct cilia. About half of the patients have defects of laterality, usually complete mirror-image reversal of the left-right axis (situs inversus) and this association is known as Kartagener syndrome (OMIM 244400). The defects in left-right axis determination associated with primary ciliary dyskinesia are proposed to result from dysfunction of the embryonic node monocilia during development. ${ }^{10-12}$

Primary ciliary dyskinesia has an incidence of 1 in 20000 with enrichment in certain populations. ${ }^{913}$ Diagnosis is made on brushings or biopsy of nasal epithelium by demonstration of abnormal ciliary beating, and by demonstration of ultrastructural defects of cilia by electron microscopy. ${ }^{14}{ }^{15}$ Primary ciliary dyskinesia is a chronic condition with symptoms present from birth but there is significant variation both in clinical severity and the age at which the condition is diagnosed. ${ }^{915} 16$ There is usually a progressively greater impact on health from the second decade onwards, producing significant morbidity and life style restriction. ${ }^{17}$ In some cases of severe lung damage, heart-lung transplantation is required ${ }^{18}$ and in general patients greatly benefit from early diagnosis and management. ${ }^{16}{ }^{19}$

Primary ciliary dyskinesia is a phenotypically heterogeneous condition associated with a variety of ultrastructural abnormalities of the cilia and sperm flagella. These include absent dynein arms (approximately $70-80 \%$ of cases), absent radial spokes $(5-10 \%)$, absent central pair microtubules, other rarer microtubular defects, and random ciliary orienta-

\section{Key points}

- Primary ciliary dyskinesia is an autosomal recessive disorder characterised by recurrent sinopulmonary infections, bronchiectasis, and subfertility, due to dysfunction of the cilia. Fiffy percent of patients with primary ciliary dyskinesia have defects of laterality (situs inversus) and this association is known as Kartagener syndrome. Primary ciliary dyskinesia has an estimated incidence of 1 in 20000 live births.

- To identify loci for this genetically heterogeneous condition, genome wide linkage scans and subsequent fine mapping were performed in two different isolated populations with distinct ciliary ultrastructural defects, from the Faroe Islands and the Druze community in northern Israel.

- A locus was mapped in seven families from the Faroe Islands to a $2.8 \mathrm{cM}$ interval on chromosome 16p12.112.2 , with a maximum lod score of 3.15 , obtained using GENEHUNTER. A locus was mapped in three out of four Druze families from the Golan region of Israel to a $17 \mathrm{cM}$ region on chromosome 15q13.1-15.1, with a maximum hlod score of 3.2 at $\alpha$ (proportion of linked families) $=0.7$, using GENEHUNTER.

- This study provides further evidence of the genetic heterogeneity underlying primary ciliary dyskinesia and has established a framework to facilitate isolation of two genes for primary ciliary dyskinesia. Determining the molecular basis of primary ciliary dyskinesia will provide insight into the genetic control of cilia assembly and function and the pathway which determines the vertebrate left right axis.

tion. ${ }^{20-22}$ Genetic linkage analysis and mutational studies in patients with primary ciliary dyskinesia have shown that this disease is genetically heterogeneous, even within groups of families with the same specific ultrastructural defect. ${ }^{23-27}$ An unusual probable dominant inheritance pattern has also been reported for the disease. ${ }^{28}$ Mutations in genes encoding two different axonemal outer dynein arm components (DNAII and DNAH5) have been shown to cause primary ciliary dyskinesia in a number of patients with outer dynein arm defects. ${ }^{27} 29$ Defects in another dynein, DNAHIl, have been

Abbreviation: $P C D$, primary ciliary dyskinesia 
found in a patient with Kartagener syndrome and normal cilia ultrastructure. ${ }^{26}$ The exact role of DNAHIl in primary ciliary dyskinesia has yet to be elucidated. Two other genes for primary ciliary dyskinesia have been localised: CILD2 to $19 \mathrm{q},{ }^{23}$ and another locus to $15 \mathrm{q} 24$ (M P Witt, personal communication).

To identify loci for PCD, genome wide linkage scans and subsequent fine mapping were performed in two different isolated populations with distinct ciliary ultrastructural defects, from the Faroe Islands and the Druze community in northern Israel.

The Faroes comprise a small group of islands in the North Atlantic Ocean located near Iceland, Scotland, and Norway with a relatively young population of mixed Norwegian, Danish, and British ancestry. The islands were colonised at the same time as Iceland, around 1100 years ago and the population size remained small until rapid expansion in the 1800s. The current population size is estimated at 48000 and has arisen predominantly by indigenous expansion. ${ }^{30}{ }^{31}$ The Druze community, a small middle eastern religious sect, was established slightly later, in the evelenth century $\mathrm{AD}^{32}$ Members live predominantly in defined geographical areas of southern Syria, southern Lebanon, and northern Israel and they remain isolated mainly for religious reasons. Both populations are also isolated for geographical and cultural reasons, in the Faroe Islands associated with limited immigration $^{30}{ }^{31}$ and in the Druze with a high level of consanguinity. ${ }^{33}$

With relatively few founders, a limited population size, and recent expansion, the Faroes and Druze populations are suitable for genetic mapping of a heterogeneous recessive disease. This has been demonstrated in the Faroe Island population, in which enrichment of disease incidence associated with specific gene mutations due to founder effects has been shown for cystic fibrosis and glycogen storage disease IIIA. ${ }^{34}{ }^{35}$ Similar findings have been reported for several conditions in the well studied Druze population including cystic fibrosis, ${ }^{36}$ Krabbe disease $^{37}$ and mucolipridosis. ${ }^{38}$ However the Druze population has not always proved to be genetically homogeneous. ${ }^{39}$

We report here the identification of two new PCD loci in these genetic isolates, located on chromosomes 16pl2.1-12.2 and 15q13.1-15.1 in the Faroe Island and Druze population respectively.

\section{SUBJECTS AND METHODS}

This study was carried out using the two family sets shown in fig 1. Informed consent was obtained in accordance with protocols approved by the University College London Hospital NHS Trust ethical committee. The diagnosis of affected subjects was made according to established clinical criteria ${ }^{9}$ supported by abnormal ciliary motility studies and electron microscopy of brushings or biopsy of nasal mucosa.

The Faroe Island resource consisted of seven families comprising 11 affected and 24 unaffected individuals (fig lA). Clinical findings for some of the patients have been described previously. ${ }^{19}$ Only the affected child in UCL140 exhibited situs inversus. Electron microscopy defined an ultrastructural phenotype of absent outer dynein arms in Faroe patients (fig 2B). The patients were Faroese in origin, living on three of the islands only, except for the father in family UCL140, who was from Denmark. The families were treated as unrelated pedigrees in linkage analysis. There was unsupported verbal evidence for distant relatedness between families UCL96, UCL97, and UCL109, however no formal genealogical analysis has been possible to establish the precise relationships. There was one affected parent, the mother in family UCL98.
Four Druze Israeli families were studied comprising 7 affected and 22 unaffected individuals (Three are shown in fig 1B). The parents in three families, UCL122, UCL124, and UCL125, were first cousins, while the fourth family, UCL123, was non-consanguineous. In contrast to the Faroe Island population, Druze patients showed an unusually high incidence of situs inversus (six out of seven affected children). Electron microscopy defined an ultrastructural phenotype of partial absence of the inner dynein arms (fig 2C). Nasal brushings were processed for ultrastructural studies using established techniques ${ }^{41}$ and over 100 suitably oriented cross sections of cilia throughout the section were examined to confirm this structural defect. The four families were located in two neighbouring Druze villages comprising 7500 inhabitants, in the mountainous region of the Golan Heights. Families UCL122 and UCL124 were from one village and families UCL123 and UCL125 were from the other.

All of the patients with primary ciliary dyskinesia who were recognised within the two populations were ascertained and there is considerable population enrichment for primary ciliary dyskinesia in both the Faroe Island and Druze populations. The prevalence of primary ciliary dyskinesia in the Faroe Islands is around 1:4500 whilst the local prevalence amongst the Druze population studied is as high as $1: 1000$.

Genome wide scans of $10 \mathrm{cM}$ density were performed in these two populations using four of the Faroe Island pedigrees (UCL96, 97, 98, and 109) and all four Druze pedigrees (UCL122, 123, 124, and 125). Genomic DNA was extracted from white blood cells using standard methodology. ${ }^{42}$ Over 350 hundred microsatellite markers from the Généthon map $^{43}$ were genotyped in each family by polymerase chain reaction and fluorescent based semi-automated methodology using methods previously described..$^{24}$ Alleles were assigned using Genescan and Genotyper software (Applied Biosystems). Linkage analysis was performed under the assumption of autosomal recessive inheritance with a penetrance of 0.9 , a disease allele frequency of 0.007 with equal allele frequencies (0.1) for each marker and a phenocopy rate of 0.00001 . This disease allele frequency reflects the worldwide incidence of primary ciliary dyskinesia of 1:20 000. Analysis was also performed using the disease allele frequencies that reflected more closely the actual population frequencies we have determined for each population as described above: 0.015 for the Faroe Island families (incidence 1:4500) and 0.03 for the Druze families (incidence $1: 1000)$. Multipoint analyses were performed using the GENEHUNTER program.

For subsequent fine mapping, six novel microsatellites were determined in the laboratory from the genomic sequence of BAC clones spanning the selected region. The primer pairs used to amplify these polymorphisms were: 5' -TGTTTCCTAGACGTGGTCAGC-3'/5' -ACTTGTACCTTTCAAA CG-3' (16/4125), 5'-TGCAAACAGACTAGGACCAC-3'/5' GGTCTCAAACTCCTGAGCTC-3' (16/10321), 5'-CACGCCTGG CTAGACTAATG-3'/5' -CTTTACCCAGTGCACATACC-3' (15/14), 5'-GTCCCTATGCAACTTTCCAC-3'/5' -GAATGTGTTTCCCGCTC TC-3' (15/20), 5' -TCTCACCAGAACCGAGAAAG-3' ${ }^{\prime} 5^{\prime}-$ GGTGCCCGCCTATAATCC-3' (15/23) and ${ }^{\prime}$ 'GAGTACCACCACTCAATCAAGG-3' $/ 5^{\prime}$-CTCAGCAGCAGTTGT TCAAG-3' (15/36).

Haplotypes were manually constructed using the most parsimonious allele configuration to minimise recombinants. Généthon marker order and genetic distances were determined from the deCODE Genetics high resolution genetic map..$^{40}$ Additional markers were positioned in the deCODE framework map based on their relative position within the human genome sequence available from the UCSC Genome Browser, April 2003 Build 33 sequence freeze. ${ }^{45}$ 


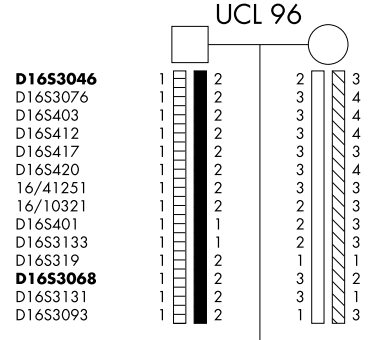

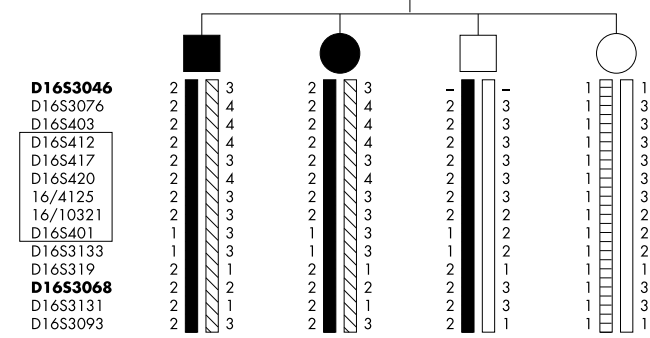
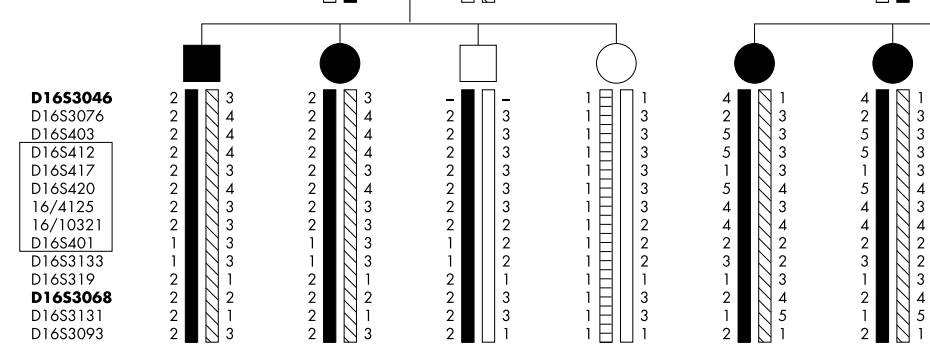

UCL 97
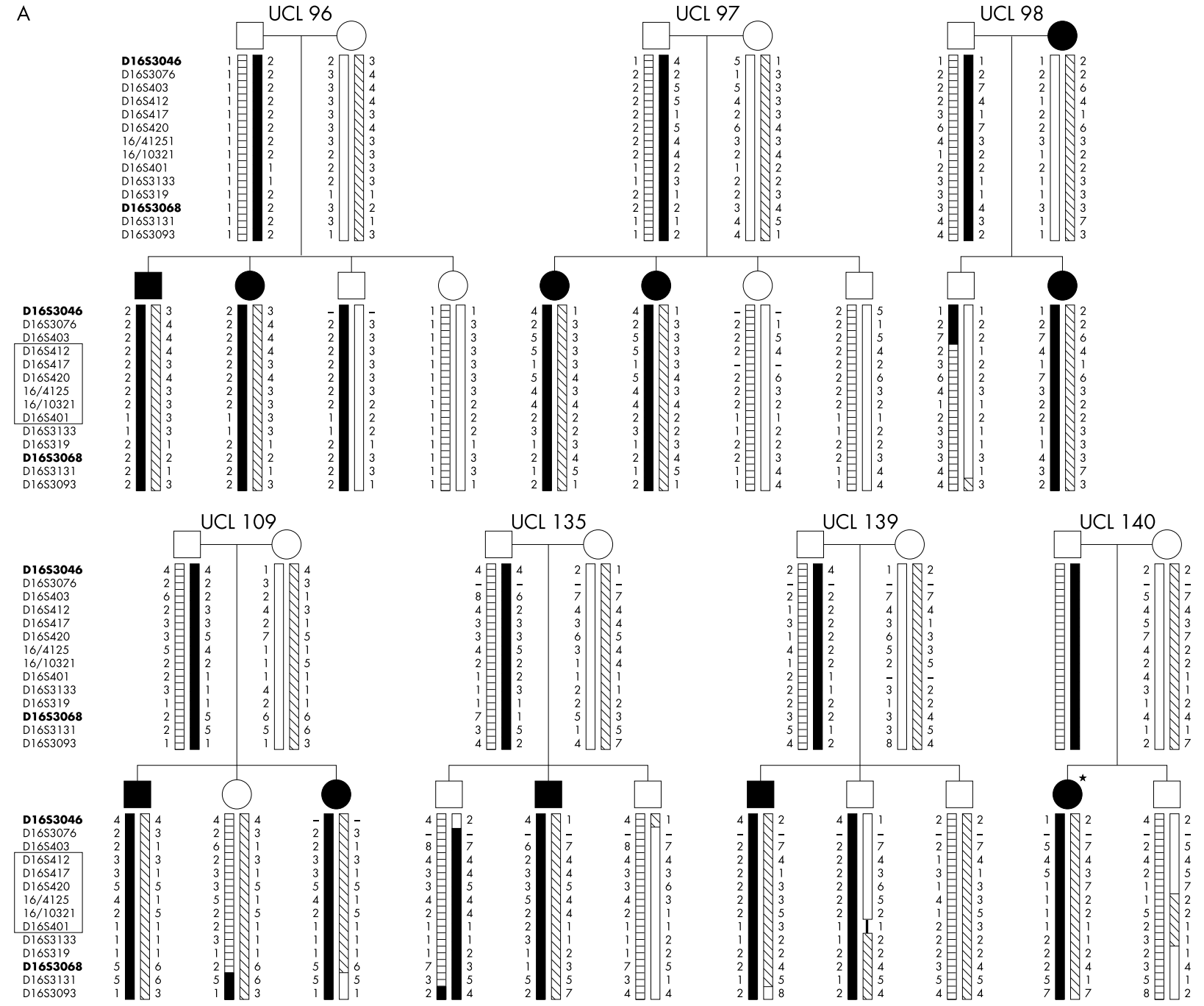

B
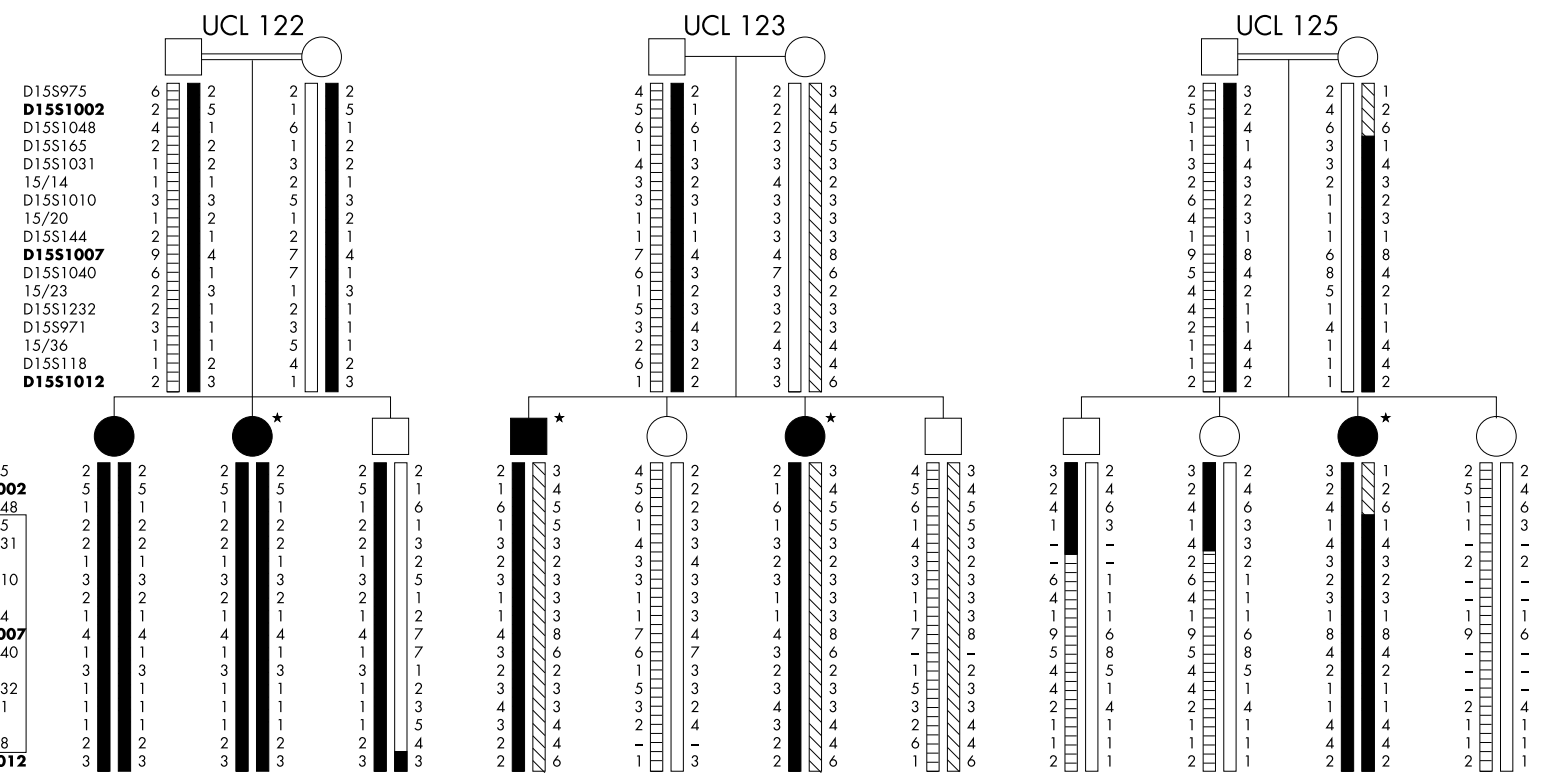

Figure 1 Pedigrees consistent with linkage on chromosome 16p12.1-12.2 and 15q13.1-15.1. (A) Faroe Island and (B) Druze Israeli haplotypes. Filled symbols indicate individuals affected with primary ciliary dyskinesia, asterisks indicate patients with situs inversus, and a double line indicates first cousin marriage. Genetic markers used in the initial genome scan are shown in bold and the box indicates the minimum critical interval encompassing each locus. For each marker, alleles are coded numerically such that the same allele number correlates to the same allele size across families. The frameworks of microsatellite markers used were as follows with genetic distances indicated in Kosambi cM: D16S3046, 2.59; D16S3076, 0.003; D16S403, 0.1; D16S412, 0.5; D16S417, 1.3; UCL420, 0.36; 16/4125, 0.4; 16/10321, 0.16; D16S401, 0.01; D16S3133, 0.31; D16S319, 0.69; D16S3068, 0.99; D16S3131, 1.55; D16S3093, and D15S975, 2.09; D15S1002, 6.02; D15S1048, 1.57; D15S165, 1.99; D15S1031, 0.22; 15/ 14, 1.38; D15S1010, 1.19; 15/20, 0.87; D15S144, 0.57; D15S1007, 1.09; D15S1040, 0.96; 15/23, 0.92; D15S1232, 0.88; D15S971, 0.27; 15/36, 1. 12: D15S118, 4.02; D15S1012. Genetic distances were taken from the DeCODE map ${ }^{39}$ except for markers $16 / 4125,16 / 10321$ D16S319, 15/14, D15S1010, 15/20, 15/23, D15S1232 and 15/36. These were positioned relative to the DeCODE marker framework using Human Genome Project draft sequence information as described in the text. 


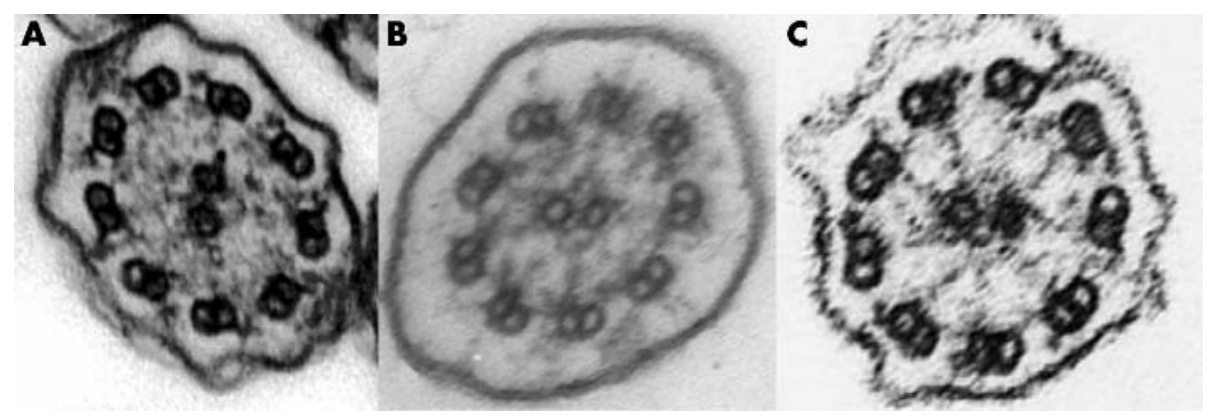

Figure 2 Electron micrographs of cross sections of respiratory cilia from patients with primary ciliary dyskinesia. (A) Normal individual with 9+2 microtubule arrangement with intact outer and inner dynein arms. (B) Faroe Island individual with absent outer dynein arm defect. (C) Druze Israeli individual with partially absent inner dynein arm defect.

Physical distances were taken from this genomic sequence map.

\section{RESULTS}

A region consistent with linkage in the four Faroe Island families was identified on chromosome 16p12.1-13.1. No evidence for linkage at any of the known PCD loci was found. Fine mapping was undertaken in the entire seven family resource which included the three additional families UCL135, UCL139, and UCL140. Linkage analysis using GENEHUNTER was performed across a $9 \mathrm{cM}$ region between markers D16S3046 and D16S3093. This gave a maximum multipoint lod score of 3.15 between markers D16S412 and 16/10321. Using a disease allele frequency calculated from the actual recorded Faroe Island population disease incidence rather than worldwide incidence of primary ciliary dyskinesia, the maximum lod score obtained was 3.13. This is probably a conservative estimate of the true degree of linkage as the families were only analysed as unrelated pedigrees. Haplotype analysis indicated the key recombinant events defining the critical region on chromosome 16pl2.1-12.2 (fig 1A). A paternal recombination in family UCL98 at Dl6S403 defined the telomeric limit of the region. The centromeric limit was defined by a maternal recombination event in family UCL139 at D16S3133. The D16S403-D16S3133 critical interval spans $2.8 \mathrm{cM}$ which corresponds to a physical distance of $2.37 \mathrm{Mb}$.

Although no statistically significant evidence of a common disease associated haplotype amongst the families could be proven, three markers in the D16S403-D16S3133 interval did show a suggestion of linkage disequilibrium with a higher frequency of certain alleles on disease chromosomes compared to control chromosomes. The control data were taken from genotypes on the families' obligate normal chromosomes and on chromosomes from a small set of unrelated Faroe control individuals. The three markers were 16/4125, D16S401, and D16S3133, with $\mathrm{p}<0.1$ for all three using Fisher's exact test. At $16 / 4125$ allele 2 was present on $3 / 15$ (20\%) of disease and $1 / 25(4 \%)$ of control chromosomes; D16S401 allele 2 was present on $6 / 15(40 \%)$ of disease and $7 / 25(28 \%)$ of control chromosomes; and D16S3133 allele 1 was present on 8/15 (53\%) disease and 3/13 (23\%) of control chromosomes. All other markers in the entire D16S3046-D16S3093 interval were non-significant. It was also noted that the affected child in family UCL98 is homozygous for the haplotype 3-2-2 at markers 16/4125-16/ 10321-D16S401.

Data from one additional Faroe Island pedigree were not included in the present study. Exclusion from the chromosome 16 locus was indicated in this family suggesting the possibility of locus heterogeneity amongst Faroe Islanders. However clinical data on the individual who appears to be recombinant across the region if affected remains incomplete and the affection status of this individual remains uncertain at present.

Three out of four of the Druze families were consanguineous and a homozygosity mapping approach ${ }^{46}$ was used. Genome scan markers were scored for homozygosity in the affected individuals in families UCL122, UCL124, UCL125, and for consistency of linkage in the non-consanguineous family UCL123. Four regions of excess homozygosity were identified on chromosomes 1q32, 3p25, 5q33, and 15q13. Fine mapping using additional markers at each region resulted in exclusion of all regions except that on chromosome 15q13. Linkage analysis using GENEHUNTER across a 25 cM region between markers D15S975 and D15S1012 gave a maximum multipoint lod score between markers D15S1031 and D15S118 of 3.2 allowing for heterogeneity, at $\alpha$ (proportion of linked families) $=0.73$ which suggested that three out of four families were linked. Using a disease allele frequency calculated from the actual recorded Druze population disease incidence rather than worldwide incidence of primary ciliary dyskinesia, the maximum lod score obtained dropped to 3.0. Haplotype analysis confirmed linkage in families UCL122, UCL123, and UCL125, but not in UCL124. No evidence for linkage of family UCL124 to any of the known PCD loci was found. The key recombination events defining the critical region were determined (fig 1B). The centromeric and telomeric limits of the region were defined by loss of homozygosity at D15S1048 in the affected child in UCL125 and a maternal recombination in family UCL122 at D15S1012 respectively. The D15S1048-D15S1012 critical interval on chromosome 15q13.1-15.1 spans a region of $17 \mathrm{cM}$, corresponding to a physical distance of $9.1 \mathrm{Mb}$. Interestingly the non-consanguineous family UCL123 was homozygous by descent for alleles at the markers D15S1031, 15/14, D15S1010, $15 / 23$, and D15S1232, identifying these as regions of potential interest if the families harbour a single ancestral mutation. However the significance is reduced since there was no evidence of allele sharing amongst affected Druze patients.

\section{DISCUSSION}

These results provide statistically significant support for loci for primary ciliary dyskinesia on chromosomes 16pl2.1-12.2 and 15q13.1-15.1. Since primary ciliary dyskinesia is a genetically and clinically heterogeneous disorder the selection of patients with an identical ultrastructural phenotype and families from isolated populations should minimise the risk of genetic heterogeneity. The incidence of inbreeding is often high in these populations which may allow the application of homozygosity or linkage disequilibrium mapping to identify and refine the disease gene localisation. This is a powerful approach ${ }^{46}$ and has proved successful in mapping many autosomal recessive diseases including 
primary ciliary dyskinesia, even in the presence of heterogeneity. ${ }^{24} 4748$ This study uses PCD family groups from two genetically isolated populations from the Faroe Islands and the Golan Heights Druze community, both of which were founded and have expanded relatively recently. There is significant enrichment for primary ciliary dyskinesia in both these populations presumably due to isolation and inbreeding, the incidence being around 1:4500 in the Faroe Islands and 1:1000 in the Druze population studied.

In both populations the initial assumption was that the existence of single ancestral Faroe Island or Druze mutation would account for all the patients in each group. However, in the present study such linkage disequilibrium has not been detected. At the Faroes locus no common haplotype was observed among the affected subjects even amongst families UCL96, UCL97, and UCL109, who may be interrelated, and the allele sharing observed was not statistically significant. Identification of linkage disequilibrium by additional marker typing at both loci would be useful to further refine the critical interval and pinpoint the localisation of the disease gene.

The extent of linkage disequilibrium encompassing a disease gene allele is dependent of course on a number of factors including natural selection and physical features such as the local recombination and gene conversion rate. Population scale effects include the population size, demographic and admixture history. A large population under mutation drift equilibrium displays low levels of linkage disequilibrium while high linkage disequilibrium correlates with a small population due to genetic drift. If the population is reduced, then allelic diversity is lowered and genetic drift is increased. Simulation studies on human populations predicts that slow early growth, such as that which occurred in the Faroes population, can be a key factor in increasing the extent of linkage disequilibrium in an isolated population. ${ }^{49} 50$ The age of the disease and marker alleles can be regarded as one of the most important considerations; the exact timing of the primary ciliary dyskinesia gene mutation in terms of when it occurred within the population will influence the extent to which it has expanded in the population. If the ancestral mutation is very ancient the region of linkage disequilibrium may have been eroded by ancient recombinations leaving it extremely small.

We have demonstrated locus heterogeneity in the PCD Druze families since only three of the four families are linked to the $15 \mathrm{q}$ locus. Moreover the lack of allele sharing suggests allelic heterogeneity. The intense inbreeding within this community could allow different mutations on different haplotypes of a disease gene to expand within the population giving rise to allelic heterogeneity. It has been suggested that multiple mutations in a single specific gene in a small geographic area and in inbred families may in fact be a common phenomenon. ${ }^{51}{ }^{52}$ Such allelic heterogeneity has been well described in previous molecular genetic studies in the Druze population. Three different iduronidase mutations were found to cause Hurler syndrome in Druze patients from the Galilee region of Israel $^{53}$ and five different mutations in the arylsulfatase A gene causing metachromatic leucodystrophy, occurring on at least three different haplotypes, were reported in the same region..$^{54}$ Two different mutations and three different genotypes were noted in a small Druze kindred with Wilson's disease. ${ }^{55}$

Both critical regions on chromosome 16p12.1-12.2 and 15q13.1-15.1 contain no obvious candidate genes based on known or predicted function or association with axonemal function. The disease genes may therefore encode proteins with a novel structural or regulatory role in cilia or flagella, associated with distinct outer (Faroe Island) and inner
(Druze) dynein arm functions. From published reports and expressed sequence tag, protein and gene prediction annotation derived from the UCSC Genome Browser, RefSeq, NCBI Map Viewer, Ensembl transcript and human cDNA collections, ${ }^{45}{ }^{56}$ the chromosome 16pl2.1-12.2 critical region contains 15 distinct genes verified with strong experimental support, and three predicted genes. Using the same criteria the chromosome 15q13.1-15.1 critical region contains 25 well supported genes and 15 predicted genes.

With the identification of two new loci for primary ciliary dyskinesia, the two candidate intervals defined on chromosomes 16p12.1-12.2 and 15q13.1-15.1 provide a framework for the isolation of the putative genes causing primary ciliary dyskinesia. The evolutionary conservation of cilia and flagella structure and function and of the genes encoding axonemal proteins has previously been used to facilitate isolation of human PCD genes. ${ }^{26} 2729$ Along with advances in the human genome project there has been huge progress with the genome projects for the flagellated PCD model organisms Chlamydomonas and Trypanosoma. ${ }^{57-59}$ Their genome sequence information and annotation is publicly available (http:// genome.jgi-psf.org/chlrel/chlrel.home.html, http://parsunl. path.cam.ac.uk/overview.htm) and it is now possible to incorporate cross species comparative genomics into the bioinformatics based prioritisation of PCD candidate genes. Technical advances in genetic manipulation of these model organisms are also of great potential value, for example for screening for a flagellar phenotype in mutant Chlamydomonas and Trypanosoma strains in which the expression of homologues of PCD candidate genes has been ablated by RNA interference. ${ }^{60-62}$

Another postgenomic approach applied to the study of cilia structure and function is also likely to prove useful in the search candidate genes for primary ciliary dyskinesia. Ostrowski and colleagues recently reported results from the first proteomic analysis of the human ciliary axoneme, aimed at characterising all the constitutive protein components. ${ }^{63}$ In this study one and two dimensional gel electrophoresis of cilia from human bronchial epithelial biopsy produced a map of over 200 putative axonemal proteins, yielding many potentially novel components of this complex organelle. Our own bio-informatic analysis has indicated that none of the available protein sequences from this study correspond to gene products predicted to map to either the 16p12.1-12.2 or the 15q13.1-15.1 loci. Ciliary actin identified in the proteomic set does have domain similarity to both a cardiac specific and a skeletal muscle specific actin isoform located in the critical region on chromosome 15 but there does not appear to be a functional correlation. Proteomic studies such as this have enormous promise and are highly appropriate for analysis of the cilium. Techniques for more direct analysis of complex protein mixtures using methods based on mass spectrometry and the development of protein "chips" are actively evolving fields which will further advance this approach. ${ }^{64}$

In conclusion, this study reinforces the value of isolated human populations in gene mapping of heterogenous disorders. Determining the molecular basis of primary ciliary dyskinesia will provide insight into the genetic control of cilia assembly and function and the pathway which determines the vertebrate left-right axis.

\section{ACKNOWLEDGEMENTS}

We are grateful to the populations of the Faroe Islands and Israel Golan Heights and to all the individuals who participated in this study. We thank Drs Michael Dunn, Amanda Walne, Martin Gray and Ms Laure Boudery for clinical ascertainment and technical support. We thank Drs Christopher O'Callaghan and Wendy Stannard for the electron micrograph of a normal axoneme. 


\section{Authors' affiliations}

D Jeganathan, R Chodhari, M Meeks, R M Gardiner, E M K Chung, H M Mitchison, Department of Paediatrics and Child Health, Royal Free and University College Medical School, University College London, UK O Færoe, Landssjukrahusid, Department of Paediatrics, Torshavn, Faroe Island

D Smyth, MRC Geneservice, Babraham Bioincubator, Babraham, Cambridge, UK

K Nielsen, Pulmonary Service, Department of Paediatrics, Righospitalet, National University Hospital, Copenhagen, Denmark

I Amirav, A S Luder, Paediatric Pulmonary Unit, Sieff Hospital, Safed, Israel

H Bisgaard, COPSAC Clinical Research Unit, Copenhagen University Hospital, Gentofte, Copenhagen, Denmark

This work was supported by the Wellcome Trust.

*Both authors have contributed equally to the work.

†Present address: Neonatal Unit, Leicester General Hospital, Gwendolen Road, Leicester.

Competing interests: none declared.

Correspondence to: Dr Hannah Mitchison, Department of Paediatrics and Child Health, Royal Free and University College Medical School, Rayne Building, 5 University Street, London WC1E 6JJ; hmitchis@ucl.ac.uk

Received 8 September 2003

Revised version received 24 October 2003

Accepted 20 November 2003

\section{REFERENCES}

1 Afzelius BA. A human syndrome caused by immotile cilia. Science 1976;193:317-9.

2 Sleigh MA, Blake JR, Liron N. The propulsion of mucus by cilia. Am Rev Respir Dis 1988; 137:726-41.

3 Katz DF, Berger SA. Flagellar propulsion of human sperm in cervical mucus. Biorheology 1980;17:169-75.

4 Piperno G, Huang B, Luck DJ. Two-dimensional analysis of flagellar proteins from wild-type and paralyzed mutants of Chlamydomonas reinhardtii. Proc Natl Acad Sci U S A 1977;74:1600-4.

5 Dutcher SK. Flagellar assembly in two hundred and fifty easy-to-follow steps. Trends Genet 1995;11:398-404.

6 Fawcett DW, Porter KR. A study of the fine structure of ciliated epithelia. $J$ Morphol 1954:94:221-64.

7 Porter ME, Sale WS. The 9+2 axoneme anchors multiple inner arm dyneins and a network of kinases and phosphatases that control motility. J Cell Biol 2000; 151:F37-42.

8 King SM. Organization and regulation of the dynein microtubule motor. Cell Biol Int 2003;27:213-5.

9 Meeks M, Bush A. Primary ciliary dyskinesia (PCD). Pediatr Pulmonol 2000;29:307-16

10 Supp DM, Potter SS, Brueckner M. Molecular motors: the driving force behind mammalian left-right development. Trends Cell Biol 2000;10:41-5.

11 Schneider H, Brueckner M. Of mice and men: dissecting the genetic pathway that controls left-right asymmetry in mice and humans. Am J Med Genet 2000 $97 \cdot 258-70$

12 McGrath J, Somlo S, Makova S, Tian X, Brueckner M. Two populations of node monocilia initiate left-right asymmetry in the mouse. Cell 2003;114:61-73.

13 Bush A, O'Callaghan C. Primary ciliary dyskinesia. Arch Dis Child 2002;87:363-5, discussion 363-5.

14 Rutland J, Griffin W, Cole P. Nasal brushing and measurement of ciliary beat frequency. An in vitro method for evaluating pharmacologic effects on human cilia. Chest 1981;80(suppl 6):865-7.

15 Bush A, Cole P, Hariri M, Mackay I, Phillips G, O'Callaghan C, Wilson R, Warner JO. Primary ciliary dyskinesia: diagnosis and standards of care. Eur Respir J 1998;12:982-8.

16 Coren ME, Meeks M, Morrison I, Buchdahl RM, Bush A. Primary ciliary dyskinesia: age at diagnosis and symptom history. Acta Paediatr 2002;91:667-9.

17 McManus IC, Mitchison HM, Chung EMJ, Stubbings GF, Martin N. Primary Ciliary Diskinesia (Siewert's/Kartagener's Syndrome): respiratory symptoms and psycho-social impact. BMC Pulm Med 2003;3:4

18 Cowan MJ, Gladwin MT, Shelhamer JH. Disorders of ciliary motility. Am J Med Sci $2001 ; 321: 3-10$

19 Ellerman A, Bisgaard H. Longitudinal study of lung function in a cohort of primary ciliary dyskinesia. Eur Respir J 1997;10:2376-9.

20 Palmblad J, Mossberg B, Afzelius BA. Ultrastructural, cellular, and clinical features of the immotile-cilia syndrome. Annu Rev Med 1984;35:481-92.

21 Greenstone M, Rutman A, Dewar A, Mackay I, Cole PJ. Primary ciliary dyskinesia: cytological and clinical features. Q J Med 1988;67:405-23.
22 De longh RU, Rutland J. Ciliary defects in healthy subjects, bronchiectasis, and primary ciliary dyskinesia. Am J Respir Crit Care Med 1995; 151:1559-67.

23 Blouin JL, Meeks M, Radhakrishna U, Sainsbury A, Gehring C, Sail GD, Bartoloni L, Dombi V, O'Rawe A, Walne A, Chung E, Afzelius BA, Armengot $M$, Jorissen $M$, Schidlow DV, van Maldergem $L$, Walt $H$, Gardiner RM, Probst D, Guerne PA, Delozier-Blanchet CD, Antonarakis SE. Primary ciliary dyskinesia: a genome-wide linkage analysis reveals extensive locus heterogeneity. Eur J Hum Genet 2000;8:109-18.

24 Meeks M, Walne A, Spiden S, Simpson H, Mussaffi-Georgy H, Hamam HD Fehaid EL, Cheehab M, Al-Dabbagh M, Polak-Charcon S, Blau H, O'Rawe A, Mitchison HM, Gardiner RM, Chung E. A locus for primary ciliary dyskinesia maps to chromosome 19q. J Med Genet 2000;37:241-4.

25 Guichard C, Harricane MC, Lafitte JJ, Godard P, Zaegel M, Tack V, Lalau G, Bouvagnet $P$. Axonemal dynein intermediate-chain gene (DNAIl) mutations result in situs inversus and primary ciliary dyskinesia (Kartagener syndrome). Am J Hum Genet 2001;68:1030-5.

26 Bartoloni L, Blouin JL, Pan Y, Gehrig C, Maiti AK, Scamuffa N, Rossier C, Jorissen $M$, Armengot $M$, Meeks M, Mitchison HM, Chung EM, DelozierBlanchet CD, Craigen WJ, Antonarakis SE. Mutations in the DNAHI 1 (axonemal heavy chain dynein type 11) gene cause one form of situs inversus totalis and most likely primary ciliary dyskinesia. Proc Natl Acad Sci U S A 2002;99: 10282-6

27 Olbrich H, Haffner K, Kispert A, Volkel A, Volz A, Sasmaz G, Reinhardt R, Hennig S, Lehrach $H$, Konietzko N, Zariwala M, Noone PG, Knowles M, Mitchison HM, Meeks M, Chung EM, Hildebrandt F, Sudbrak R, Omran H. Mutations in DNAH5 cause primary ciliary dyskinesia and randomization of left-right asymmetry. Nat Genet 2002;30:143-4.

28 Narayan D, Krishnan SN, Upender M, Ravikumar TS, Mahoney MJ, Dolan TF Jr, Teebi AS, Haddad GG. Unusual inheritance of primary ciliary dyskinesia (Kartagener's syndrome). J Med Genet 1994;31:493-6.

29 Pennarun G, Escudier E, Chapelin C, Bridoux AM, Cacheux V, Roger G, Clement A, Goossens M, Amselem S, Duriez B. Loss-of-function mutations in a human gene related to Chlamydomonas reinhardtii dynein IC78 result in primary ciliary dyskinesia. Am J Hum Genet 1999;65:1508-19.

30 West JF. Faroe: the emergence of a nation. London: C Hurst, 1972.

31 Jorgensen TH, Degn B, Wang AG, Vang M, Gurling H, Kalsi G, McQuillin A, Kruse TA, Mors O, Ewald $\mathrm{H}$. Linkage disequilibrium and demographic history of the isolated population of the Faroe Islands. Eur J Hum Genet 2002;10:381-7.

32 Swayd SS. The Druzes: an annotated bibliography. Kirkland, WA: ISES Publications, 1988

33 Vardi-Saliternik R, Friedlander Y, Cohen T. Consanguinity in a population sample of Israeli Muslim Arabs, Christian Arabs and Druze. Ann Hum Biol 2002;29:422-31.

34 Schwartz M, Sorensen N, Brandt NJ, Hogdall E, Holm T. High incidence of cystic fibrosis on the Faroe Islands: a molecular and genealogical study. Hum Genet 1995;95:703-6.

35 Santer R, Kinner M, Steuerwald U, Kjaergaard S, Skovby F, Simonsen H, Shaiu WL, Chen YT, Schneppenheim R, Schaub J. Molecular genetic basis and prevalence of glycogen storage disease type IIIA in the Faroe Islands. Eur J Hum Genet 2001 ; 9:388-91.

36 Lerer I, Laufer-Cahana A, Rivlin JR, Augarten A, Abeliovich D. A large deletion mutation in the CFTR gene $(3120+1 \mathrm{Kbdel} 8.6 \mathrm{~Kb})$ : a founder mutation in the Palestinian Arabs. Mutation in brief no 231. Online. Hum Mutat 1999;13:337.

37 Rafi MA, Luzi P, Zlotogora J, Wenger DA. Two different mutations are responsible for Krabbe disease in the Druze and Moslem Arab populations in Israel. Hum Genet 1996:97:304-8.

38 Raas-Rothschild A, Cormier-Daire V, Bao M, Genin E, Salomon R, Brewer K, Zeigler M, Mandel H, Toth S, Roe B, Munnich A, Canfield WM. Molecular basis of variant pseudo-hurler polydystrophy (mucolipidosis IIIC). J Clin Invest 2000;105:673-81

39 Adato A, Raskin L, Petit C, Bonne-Tamir B. Deafness heterogeneity in a Druze isolate from the Middle East: novel OTOF and PDS mutations, low prevalence of GJB2 35delG mutation and indication for a new DFNB locus. Eur J Hum Genet 2000;8:437-42.

40 Kong A Gudbjartsson DF, Sainz J, Jonsdottir GM, Gudjonsson SA Richardsson B, Sigurdardottir S, Barnard J, Hallbeck B, Masson G, Shlien A, Palsson ST, Frigge ML, Thorgeirsson TE, Gulcher JR, Stefansson K. A highresolution recombination map of the human genome. Nat Genet 2002;31:241-7

41 Rutland J, Cole PJ. Non-invasive sampling of nasal cilia for measurement of beat frequency and study of ultrastructure. Lancet 1980;ii(8194):564-5.

42 Miller SA, Dykes DD, Polesky HF. A simple salting out procedure for extracting DNA from human nucleated cells. Nucleic Acids Res 1988;16:1215.

43 Dib C, Faure S, Fizames C, Samson D, Drouot N, Vignal A, Millasseau P, Marc S, Hazan J, Seboun E, Lathrop M, Gyapay G, Morissette J, Weissenbach J. A comprehensive genetic map of the human genome based on 5264 microsatellites. Nature 1996;380:152-4.

44 Vulliamy T, Marrone A, Goldman F, Dearlove A, Bessler M, Mason PJ, Dokal I. The RNA component of telomerase is mutated in autosomal dominant dyskeratosis congenita. Nature 2001;413:432-5.

45 Kent WJ, Sugnet CW, Furey TS, Roskin KM, Pringle TH, Zahler AM Haussler D. The human genome browser at UCSC. Genome Res 2002;12:996-1006.

46 Lander ES, Botstein D. Homozygosity mapping: a way to map human recessive traits with the DNA of inbred children. Science 1987;236:1567-70.

47 Strautnieks SS, Thompson RJ, Hanukoglu A, Dillon MJ, Hanukoglu I, Kuhnle U, Seckl J, Gardiner RM, Chung E. Localisation of pseudohypoaldosteronism genes to chromosome 16p12.2-13.11 and 12p13.1-pter by homozygosity mapping. Hum Mol Genet 1996;5:293-9. 
48 Omran H, Haffner K, Volkel A, Kuehr J, Ketelsen UP, Ross UH, Konietzko N Wienker T, Brandis M, Hildebrandt F. Homozygosity mapping of a gene locus for primary ciliary dyskinesia on chromosome $5 p$ and identification of the heavy dynein chain DNAH5 as a candidate gene. Am J Respir Cell Mol Biol 2000;23:696-702

49 Slatkin M. Linkage disequilibrium in growing and stable populations. Genetics 1994; 137:331-6.

50 Huttley GA, Smith MW, Carrington M, O'Brien SJ. A scan for linkage disequilibrium across the human genome. Genetics 1999;152:1711-22.

51 Zlotogora J, Gieselmann V, Bach G. Multiple mutations in a specific gene in a small geographic area: a common phenomenon? Am J Hum Genet 1996:58:241-3.

52 Carrasquillo MM, Zlotogora J, Barges S, Chakravarti A. Two different connexin 26 mutations in an inbred kindred segregating non-syndromic recessive deafness: implications for genetic studies in isolated populations. Hum Mol Genet 1997:6:2163-72.

53 Bach G, Moskowitz SM, Tieu PT, Matynia A, Neufeld EF. Molecular analysis of Hurler syndrome in Druze and Muslim Arab patients in Israel: multiple allelic mutations of the IDUA gene in a small geographic area. Am J Hum Genet 1993:53:330-8

54 Heinisch U, Zlotogora J, Kafert S, Gieselmann V. Multiple mutations are responsible for the high frequency of metachromatic leukodystrophy in a small geographic area. Am J Hum Genet 1995:56:51-7.

55 Kalinsky H, Funes A, Zeldin A, Pel-Or Y, Korostishersky M, GershoniBaruch R, Farrer LA, Bonne-Tamir B. Novel ATP7B mutations causing Wilson disease in several Israeli ethnic groups. Hum Mutat 1998;11:145-51.
56 Hubbard T, Barker D, Birney E, Cameron G, Chen Y, Clark L, Cox T, Cuff J, Curwen V, Down T, Durbin R, Eyras E, Gilbert J, Hammond M, Huminiecki L, Kasprzyk A, Lehvaslaiho H, Lijnzaad P, Melsopp C, Mongin E, Pettett R, Pocock M, Potter S, Rust A, Schmidt E, Searle S, Slater G, Smith J, Spooner W, Stabenau A, Stalker J, Stupka E, Ureta-Vidal A, Vastrik I, Clamp M. The Ensembl genome database project. Nucleic Acids Res 2002;30:38-41.

57 El Zein L, Omran H, Bouvagnet P. Lateralization defects and ciliary dyskinesia: lessons from algae. Trends Genet 2003;19:162-7.

58 Shrager J, Hauser C, Chang CW, Harris EH, Davies J, McDermott J, Tamse R, Zhang Z, Grossman AR. Chlamydomonas reinhardtii genome project. A guide to the generation and use of the cDNA information. Plant Physiol 2003;131:401-8.

59 Vaughan S, Gull K. The trypanosome flagellum. J Cell Sci 2003;116:757-9.

60 Sineshchekov OA, Jung KH, Spudich JL. Two rhodopsins mediate phototaxis to low- and high-intensity light in Chlamydomonas reinhardtii. Proc Natl Acad Sci U S A 2002;99:8689-94.

61 Koblenz B, Schoppmeier J, Grunow A, Lechtreck KF. Centrin deficiency in Chlamydomonas causes defects in basal body replication, segregation and maturation. J Cell Sci 2003;116:2635-46.

62 McKean PG, Baines A, Vaughan S, Gull K. Gamma-tubulin functions in the nucleation of a discrete subset of microtubules in the eukaryotic flagellum. Curr Biol 2003; 13:598-602.

63 Ostrowski LE, Blackburn K, Radde KM, Moyer MB, Schlatzer DM, Moseley A, Boucher RC. A proteomic analysis of human cilia: identification of novel components. Mol Cell Proteomics 2002;1:451-65.

64 Pandey A, Mann M. Proteomics to study genes and genomes. Nature $2000 \cdot 405 \cdot 837-46$

\section{CORRECTION}

Venturin M, Guarnieri P, Natacci F, et al. Mental retardation and cardiovascular malformations in NF 1 microdeleted patients point to candidate genes in 17q11.2 (J Med Genet 2003;41:35-41). We would like to offer our sincere apologies to the authors of this paper for a number of errors that were introduced regarding the incorrect use of the term "learning disability". The instances of "learning disability" in the Key points box, and in Tables 1 and 2 should be "mental retardation". These errors are much regretted and the corrected versions are shown here.

Table 1 Presence of specific clinical signs in $92 \mathrm{NF} 1$ microdeleted patients $v$ NF1 patients according to published reports

\begin{tabular}{|c|c|c|c|c|c|}
\hline \multirow[b]{2}{*}{ Clinical signs } & \multicolumn{3}{|c|}{ NF1 microdeleted patients } & \multicolumn{2}{|c|}{ NF1 patients } \\
\hline & $\begin{array}{l}\text { Total } \\
\text { evaluable }\end{array}$ & $\begin{array}{l}\text { Total } \\
\text { affected }\end{array}$ & $\%$ & $\%$ & Discordance $^{*}\left(\chi^{2}\right.$ value $)$ \\
\hline Plexiform neurofibroma & 88 & 25 & 28 & 25 to 30 & No $(0.36$ to 0.13$)$ \\
\hline Macrocephaly & 63 & 20 & 32 & 40 to 50 & No (1.6 to 6.48$)$ \\
\hline Facial dysmorphisms $\dagger$ & 88 & 69 & 78 & 5 to 15 & Yes (1065.8 to 264.6 ) \\
\hline Hypertelorism & 64 & 27 & 42 & 15 & Yes $(48.60)$ \\
\hline Mental retardation & 63 & 36 & 57 & 4 to 8 & Yes (702 to 300.1$)$ \\
\hline Seizures & 56 & 5 & 9 & 3.8 to 6 & No $(7.11$ to 1.5$)$ \\
\hline \multicolumn{6}{|l|}{ Cardiovascular } \\
\hline malformations $\ddagger$ & 61 & 11 & 18 & 2.1 & Yes (120.39) \\
\hline Deafness & 82 & 2 & 2 & 5.3 & No (2.05) \\
\hline Scoliosis & 60 & 9 & 15 & 10 to 30 & No (2.5 to 7.5$)$ \\
\hline Pectus excavatum-carinatum & 58 & 10 & 17 & 20 & No $(0.45)$ \\
\hline
\end{tabular}

*The discordant values between the two groups of patients and the relative clinical signs are given in bold. tIncluding the following signs, each observed in at least one patient: coarse face, flat occiput/brachycephaly, facial asymmetry, prominent forehead, frontal bossing, ptosis, downslanting deep set eyes, eversion of the lateral eyelid, epicanthic folds, strabismus, large nose, prominent nose, high nasal bridge, broad nasal bridge, broad nose, bulbous nasal tip, large ears, low set ears, malar hypoplasia, wide philtrum, prominent philtrum, small mouth, thick lips, micrognathia, small pointed chin, low posterior hairline.

flncluding: atrial septal defect, ventricular septal defect, patent ductus arteriosus, pulmonary stenosis, dilated aortic valve, hypertrophic cardiomyopathy, mitral valve prolapse. 
Table 2 Clinical features of the 14 newly described patients carrying NF1 microdeletion characterised by refined fluorescent in situ hybridisation (FISH) analysis

\begin{tabular}{|c|c|c|c|c|c|c|c|c|}
\hline \multirow[b]{2}{*}{ Patient } & \multirow[b]{2}{*}{$\begin{array}{l}\text { Age } \\
\text { (years) }\end{array}$} & \multirow[b]{2}{*}{ Sex } & \multirow[b]{2}{*}{ Deletion type } & \multicolumn{5}{|l|}{ Clinical signs } \\
\hline & & & & Growth defects & Dysmorphic & $\begin{array}{l}\text { Mental } \\
\text { retardation }\end{array}$ & $\begin{array}{l}\text { Cardiovascular } \\
\text { malformation }\end{array}$ & Other features \\
\hline 119 & 4 & $M$ & REP & No & No & No & - & \\
\hline 118 & 5 & M & cen-REP & No & No & No & - & Optic glioma, seizures \\
\hline 93 & 6 & M & REP & 90th centile, macrocephaly & Yes* $^{*}$ & No & $\mathrm{HCM}$ & Broad neck, 3 NFs \\
\hline 65 & 6 & M & REP & $\begin{array}{l}\text { Height } 3 \text { rd centile, } \\
\text { microcephaly } 2 \text { nd centile }\end{array}$ & Yest & IQ48 & VSD (upper part) & Small hands/feet, short fingers \\
\hline 116 & 6 & M & REP & Short stature 10 th centile & Yesł & IQ54 & Mitral insufficiency & $\begin{array}{l}\text { MCLS, kyphoscoliosis, pectus } \\
\text { excavatum, genu valgus, pes } \\
\text { planus, umbilical hernia }\end{array}$ \\
\hline 72 & 7 & $M$ & REP & No & Yes§ & IQ50 & & Small hands/feet, short fingers \\
\hline 76 & 8 & $\mathrm{~F}$ & REP & No & Yes & No & - & - \\
\hline 94 & 8 & $\mathrm{~F}$ & REP & No & Yes** & No & - & - \\
\hline 75 & 9 & $\mathrm{~F}$ & REP & No & Yest† & No & - & - \\
\hline 85 & 11 & $M$ & REP & No & No & IQ77 & - & MCLS \\
\hline 7 & 11 & M & REP & No & Yesł‡ & $\begin{array}{l}\text { Speech } \\
\text { impairment }\end{array}$ & - & $\begin{array}{l}\text { MCLS, amblyopia, thalamic } \\
\text { hamartoma }\end{array}$ \\
\hline 82 & 23 & $\mathrm{~F}$ & REP & Short stature & No & No & - & Hearing impairment, Noonan-like \\
\hline 77 & $U$ & $\mathrm{~F}$ & REP & Overgrowth $>97$ th centile & Yes§§ & $\begin{array}{l}\text { Speech } \\
\text { impairment, } \\
\text { LD }\end{array}$ & - & $\begin{array}{l}\text { NFs, required special education, } \\
\text { short and broad fingers and toes }\end{array}$ \\
\hline 78 & $U$ & $\mathrm{~F}$ & REP & - & Yes ฯ & $\begin{array}{l}\text { Speech } \\
\text { impairment }\end{array}$ & - & $\begin{array}{l}\text { Delayed motor development, } \\
\text { short and broad feet, fifth finger } \\
\text { clinodactyly }\end{array}$ \\
\hline
\end{tabular}

*Hypertelorism, epicanthic folds, low set ears, low posterior hairline.

†Hypertelorism, downslanting eye, strabismus, large and prominent nose with high and broad bridge, bulbous nasal tip, large and low set ears, malar hypoplasia, wide and prominent philtrum, small mouth, small pointed chin.

†Hypertelorism, long philtrum, broad nose.

$\S$ Prominent forehead, hypertelorism, ptosis (O.DX), downslanting eyes; strabismus, large and prominent nose with high and broad bridge and bulbous nasal tip, large and low set ears, wide and prominent philtrum, low posterior hairline.

- Coarse face, hypertelorism.

${ }^{* *}, t+$ Epicanthic folds.

††Hypertelorism, broad and wild nasal bridge, broad nasal tip.

$\S \S$ Simple facial features.

- Epicanthic folds, bulbous nose, narrow high palate, low forehead.

cen-REP, deletion extending centromerically to REP-P; CVM, cardiovascular malformations; $F$, female; HCM, hypertrophic cardiomyopathy; LD, learning

disabilities; M, male; MCLS, multiple cafè-au-lait spots; NF, neurofibroma; REP, NF1 repeat mediated deletion; U, unknown; VSD, ventricular septal defect.

\section{Key points}

- NF1 microdeletion syndrome is determined by haploinsufficiency of the NFI gene and its flanking regions; NFl microdeleted patients show a more severe phenotype than observed in classical NF1 patients.

- The aim of this study was to verify the presence of specific clinical signs of NFI microdeletion, by combining clinical and genetic evidence from 92 deleted patients, 14 newly characterised and 78 already published.

- Statistical analysis, done by comparing the frequency of 10 clinical signs between NF1 microdeleted patients and the whole NFI population, showed that the most common extra-NFl clinical signs in microdeleted patients were mental retardation, cardiovascular malformations, and dysmorphisms.

- Using bioinformatic tools, the deletion gene content of 44 genetically and clinically characterised patients was established. It is proposed that haploinsufficiency of $O M G$ and/or CDK5R1 genes may be implicated in mental retardation. In relation to cardiovascular malformations, only JJAZ1 and CENTA2 can be considered as plausible candidate genes.

- When present in an NFl patient, dysmorphisms, cardiac anomalies, and mental retardation are signs indicating NF1 microdeletion.

\section{CORRECTION}

doi: 10.1136/jmg.2003.008433corr

Owing to the change over of typesetters at the BMJ Publishing Group Ltd last year, we would like to apologise for an error that was published in the paper by Baser et al $(J$ Med Genet 2003;40:758-760). In Table 2 the headings 'Classical NF2' and 'Somatic mosaic' should be indented as they are subsections of the heading 'Nonsense or frameshift'. 